\title{
Investigating the Relationship Between Psychosocial Factors with Productivity of a Food Distribution Industry Employees
}

\author{
Davood Afshari ${ }^{1}$ (D), Payam Amini2 ${ }^{\text {(D) }}$, Behnoush Jafari3*iD, Ghasem Akbari ${ }^{3}$ (D)
}

1. Associate Professor, Department of Occupational Health Engineering, School of Health, Ahvaz Jundishapur University of Medical Sciences, Ahvaz, Iran

2. Assistant Professor, Department of Biostatistics and Epidemiology, School of Health, Ahvaz Jundishapur University of Medical Sciences, Ahvaz, Iran

3. MSc Student, Department of Occupational Health Engineering, School of Health, Ahvaz Jundishapur University of Medical Sciences, Ahvaz, Iran

\begin{tabular}{|c|}
\hline Article Info \\
\hline $\begin{array}{l}\text { Received: 2020/12/25; } \\
\text { Accepted: 2021/05/06; } \\
\text { ePublished: 2021/05/18 }\end{array}$ \\
\hline doi $\underline{10.30699 / j e r g o n .9 .1 .75}$ \\
\hline $\begin{array}{l}\text { Use your device to scan } \\
\text { and read the article online }\end{array}$ \\
\hline 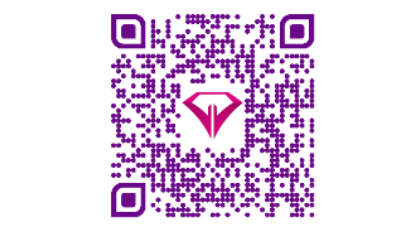 \\
\hline $\begin{array}{l}\text { Corresponding Author } \\
\text { Behnoush Jafari } \\
\text { MSc Student, Department of } \\
\text { Occupational Health Engineering, } \\
\text { School of Health, Ahvaz Jundi- } \\
\text { shapur University of Medical } \\
\text { Sciences, Ahvaz, Iran } \\
\text { Email: } \\
\text { Behnoosh.jafari@yahoo.com }\end{array}$ \\
\hline
\end{tabular}

\section{ABSTRACT}

Background and Objectives: Psychosocial factors are among the factors affecting employee productivity. Since few studies have been done in this field, this study was conducted to investigate the relationship between psychosocial factors regarding productivity.

Methods: This cross-sectional and descriptive-analytical study was conducted in 2020 among 105 employees of a food distribution company in Ahvaz. Data collection tools included demographic information questionnaire, Copenhagen Psychosocial Factors Questionnaire (COPSOQ) and Goldsmith Hershey Productivity Questionnaire. Independent t-test, one-way analysis of variance and Pearson correlation coefficient were used to investigate the relationship between variables.

Results: The results showed that there was no significant relationship between any of the demographic variables with the score of psychosocial factors and productivity $(P>0.05)$. Psychosocial factor 2 has a negative and significant relationship with the average score of productivity, ability, role clarity, organizational support, motivation, feedback and credibility. And psychosocial factor 4 has a negative and significant relationship with motivation. The mean score of psychosocial factors, factor 1 and 3 showed a positive and significant relationship with the mean score of productivity, ability, role clarity, organizational support, motivation, feedback and credibility.

Conclusion: Considering the role of psychosocial factors on employees' productivity, it is necessary to consider organizational interventions in order to control effective psychosocial factors. More attention to psychosocial factors in the workplace can play an effective role in the efficiency and productivity of employees and the organization.

Keywords: Psychosocial factors, Copenhagen psychosocial questionnaire, Productivity, Food Distribution Industry Staff

Copyright (C) 2021, This is an original open-access article distributed under the terms of the Creative Commons Attribution-noncommercial 4.0 International License which permits copy and redistribute of the material just in noncommercial usages with proper citation.

How to Cite This Article:

Jafari B, Afshari D, Amini P, Akbari G. Investigating the Relationship between Psychosocial Factors with Productivity of a Food Distribution Industry Employees. Iran J Ergon. 2021; 9 (1) :75-86 


\section{Extended Abstract}

\section{Introduction}

Nowadays, psychosocial factors in the workplace, are considered as important and emerging occupational hazards in the field of ergonomics and occupational health. The results of research in various occupations indicate that undesirable psychosocial factors are increasing in the workplace [1]. According to the World Health Organization, by 2020 , complications related to workrelated stress were the second leading cause of disability for staff [2]; therefore, identifying, evaluating and managing these factors as a priority seems necessary. Since few studies have been done in this field, this study was conducted to investigate the relationship between psychosocial factors regarding productivity.

\section{Methods}

This cross-sectional and descriptive-analytical study was conducted in 2020 among 105 employees of a food distribution company in Ahvaz. Data collection tools included demographic information questionnaire, Copenhagen Psychosocial Factors Questionnaire (COPSOQ) and Goldsmith Hershey Productivity Questionnaire.

The validity and reliability of this questionnaire were examined by Ardestani et al. Cronbach's alpha value was calculated to be 0.863 , which is acceptable for this questionnaire (17). After distributing the questionnaires among the individuals, the objectives of the project were explained to them and they were given enough time to carefully read the questionnaire and complete it with personal consent. Finally, the questionnaire was collected and statistically analyzed. Statistical analysis of the data was performed using SPSS software version 22 (SPSS Inc., Chicago, Ill., USA). Using one-way analysis of variance, independent t-test and Pearson correlation coefficient, the relationship between different factors was investigated. In this study, a significance level of $5 \%$ was considered.

\section{Results}

The results showed that there was no significant relationship between any of the demographic variables with the score of psychosocial factors and productivity $(P>0.05)$. Psychosocial factor 2 has a negative and significant relationship with the average score of productivity, ability, role clarity, organizational support, motivation, feedback and credibility. And psychosocial factor 4 has a negative and significant relationship with motivation. The mean score of psychosocial factors, factor 1 and 3 showed a positive and significant relationship with the mean score of productivity, ability, role clarity, organizational support, motivation, feedback and credibility.

\section{Discussion}

The present study was the first study to investigate the relationship between psychosocial factors in the workplace on employee productivity of one of the food distribution industries in Iran and using the Copenhagen Psychosocial Questionnaire (COPSOQ) and Hersi Goldsmith Productivity Questionnaire to assess the factors, respectively. Psychosocial and workplace productivity were performed.

The findings of the present study showed that psychosocial factor 2 (job burnout, stress, workfamily conflict and emotional demands) had a negative and significant relationship with the mean score of productivity, ability, role clarity, organizational support, motivation, feedback and credibility. And psychosocial factor N. 4 (offensive behavior) has a negative and significant relationship with motivation. In other words, with increasing burnout, stress, work-family conflict, and emotional demands, productivity, ability, role clarity, organizational support, motivation, feedback and credibility decrease. Also, with the increase of abusive behaviors, the person's motivation will decrease significantly.

Average score of psychosocial factors, psychosocial factor 1 (leadership quality, social support from supervisors, reward, dignity and respect, trust, predictability of work) and psychosocial factor 3 
(meaningful work, commitment to work, impact on work, role clarity and transparency) showed a positive and significant relationship with the mean productivity score, ability, role clarity, organizational support, motivation, feedback and credibility. The findings of the present study are consistent with the results of Hinojosa-Alcalde et al. [18].

The mean scores of psychosocial factors and productivity in the study population in the present study were 3.250 and 3.7304 , respectively. In the study of Khanehshenas et al. [19], which examined the relationship between psychosocial stressors of work and job performance among bank employees, the average score of job stress among employees was 2.75 and the average score of job performance was 2.63 which were not in line with the results of the present study, which may be due to the differences in the study population and environmental, administrative and industrial conditions.

According to the principles of macro-ergonomics, one of the principles that should be considered in business design is to meet the principle of meeting social needs in the job [20]. Failure to do so can cause job stress and health problems for employees, which can ultimately have a detrimental effect on the productivity and efficiency of the organization. The results of the present study are fully consistent with this principle; as a result, more attention should be paid to this principle in order to improve the conditions of psychosocial factors in the workplace and increase the level of employee productivity. As the findingd show, psychosocial factors are more effective than demographic factors in improving productivity. In the study of Okazaki et al. [21] as in the present study, it was shown that there is no significant relationship between demographic variables with the score of psychosocial factors and productivity.
As mentioned, psychosocial factors in the workplace are among the most important factors affecting employee productivity that are directly related to productivity. In their study, Dollard et al. [22] showed that psychosocial factors are effective in improving employee productivity and health. Maqsoom et al. [23] also showed in their study that psychosocial factors affect the productivity and health of construction workers. Ibrahim et al. also conducted a study on the relationship between psychosocial factors and health care productivity in 2019, which showed that psychosocial factors affect more than $50 \%$ of health care productivity [24]. Cho et al. [25] showed in their study that psychosocial factors in the workplace can negatively affect productivity and mental and physical health of individuals. Haider et al. [26] found a positive and significant relationship between psychosocial factors and productivity. The results of these studies are consistent with the results of the present study. To increase the validity of the results, we can refer to the results of studies by Chang et al. [27] and Husain et al. [28].

\section{Conclusion}

Considering the role of psychosocial factors on employees' productivity, it is necessary to consider organizational interventions in order to control effective psychosocial factors. More attention to psychosocial factors in the workplace can play an effective role in the efficiency and productivity of employees and the organization.

\section{Acknowledgement}

This article is based on a research project approved by the Faculty of Health of Ahvaz University of Medical Sciences with the number 99 s67. We would like to thank all the employees of the food distribution company in question, who sincerely helped us in this research.

\section{Conflict of Interest}

The authors declared no conflict of interest. 


\section{مقالة بثوهشى}

بررسى ارتباط بين عوامل روانى - اجتماعى محيط كار بر بهرهورى كاركنان يك صنعت يخش مواد غذايى

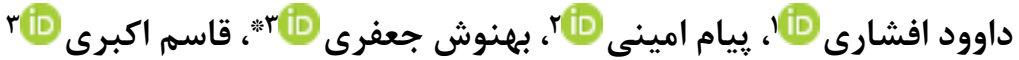

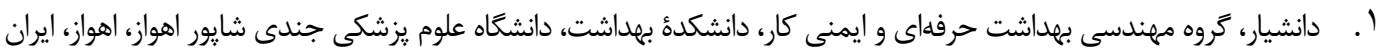

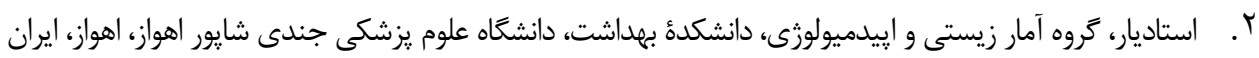

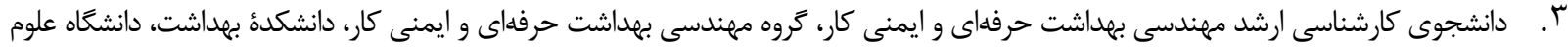

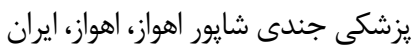

\begin{tabular}{|c|c|}
\hline خلاصه & اطلاعات مقاله \\
\hline زمينه و هدف: عوامل روانى - اجتماعى محيط كار ازجمله عوامل تأثيركذار بر بهرهورى كاركنان مىباشد. & 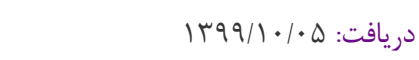 \\
\hline از آنجا كه مطالعات اندكى در اين حوزه انجام شده است، لذا اين مطالعه با هدف بررسى ارتباط بين عوامل & 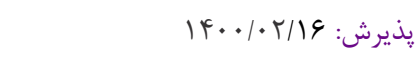 \\
\hline روانى - اجتماعى محيط كار بر بهرورى انجام شده است. & 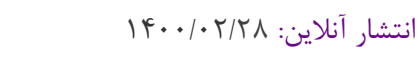 \\
\hline روش كار: مطالعة مقطعى و توصيفى- تحليلى حاضر در سال 99 إ و در بين ه. ا نفر از كاركنان يك شركت & 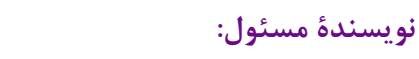 \\
\hline يخش مواد غذايى در اهواز انجام كرفت. ابزار جمعآورى اطلاعات شامل يرسشنامة اطلاعات دموكرافيكى، & 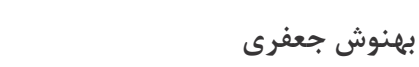 \\
\hline يرسشنامةٔ عوامل روانى - اجتماعى كينهاكن(COPSOQ) و يرسشنامة بهرهورى هرسى كلداسميت بود. & دانشجوى كارشناسى ارشد مهندسى \\
\hline بلمنظور بررسى ارتباط بين متغيرها از آزمونهاى تى تست مستقل، آزمون آناليز واريانس يكطرفه و ضريب & بهداشت حرفهاى و ايمنى كار، كروه \\
\hline همبستخى بيرسون استفاده كرديد. & مهندسى بهداشت حرفهاى و ايمنى كار، \\
\hline يافتهها: نتايج نشان داد كه بين هيج يك از متغيرهاى جمعيتشناختى با امتياز فاكتورهاى روانى - اجتماعى & دانشكدة بهداشت، دانشكاه علوم يزشكى \\
\hline و بهرهورى ارتباط معنادارى وجود ندارد (ه>/P> (P). فاكتور روانى- اجتماعى ז ارتباط منفى و معنادارى با & إيور اهواز، اهواز، ايران \\
\hline ميانكَين امتياز بعرهورى، توانايى، وضوح نقش، حمايت سازمانى، انكَيزه، بازخورد و اعتبار دارد. و فاكتور روانى- & 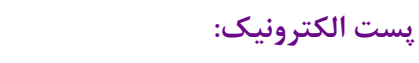 \\
\hline اجتماعى f نيز با انَيزه، ارتباط منفى و معنادارى دارد. ميانكَين امتياز فاكتورهاى روانى - اجتماعى، فاكتور 1 & behnoosh.jafari@yahoo.com \\
\hline 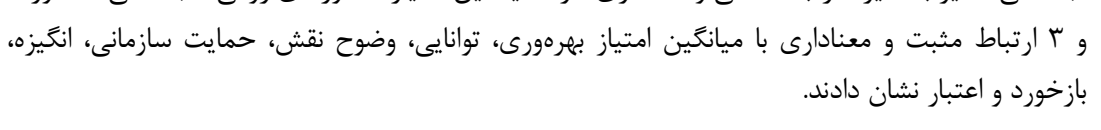 & زبر راى دانلود اينّ مقاله، كـن \\
\hline نتيجه كَيرى: ا توجه به نقش عوامل روانى - اجتماعى محيط كار بر بهرهورى كاركنان، لازم است مداخلات & 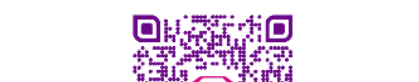 \\
\hline 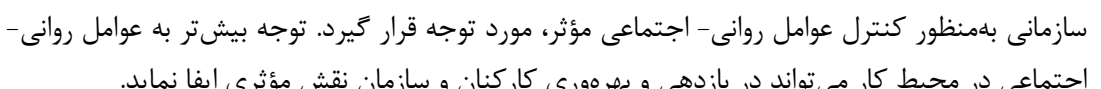 & 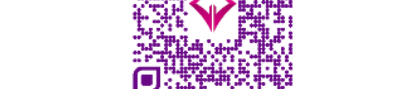 \\
\hline كواد غذايدوازها: عوامل روانى- اجتماعى، يرسشنامه روانى - اجتماعى كينهاكن، بهرهورى، كاركنان صنعت بخش & 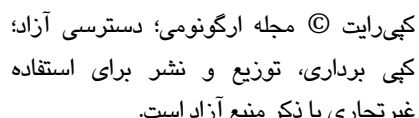 \\
\hline
\end{tabular}

مقدمه

لذا شناسايى، ارزيابى و مديريت اين عوامل بهعنوان يك اولويت، ضرورى بهنظر مىرسد.

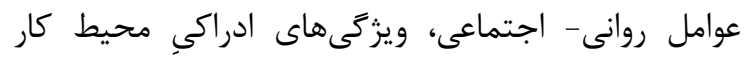

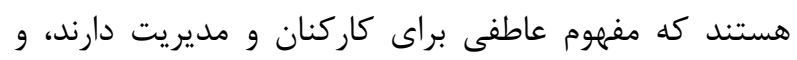

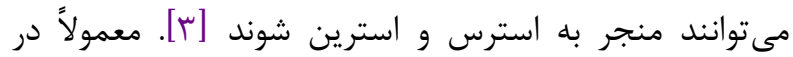
محيطهاى كارى، از فاكتورهاى روانى- اجتماعى تحت نام
در عصر حاضر عوامل روانى - اجتماعى محيط كار، از جمله

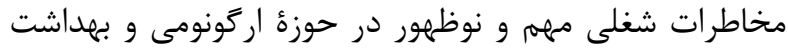

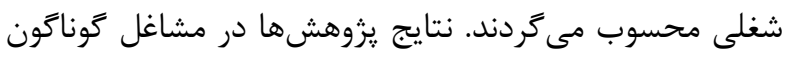

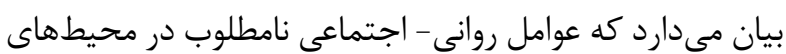

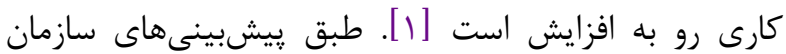
جهانى بهداشت تا سال •r.T.T عوارض مرتبط با استرسهاى

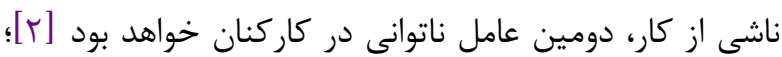


سازمان و تحميل هزينههاى بىفايده بر آن شود؛ ازاين رو آناع

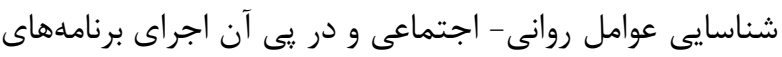

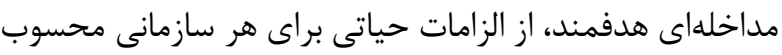

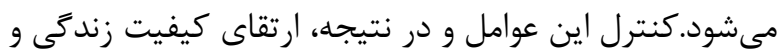
رضايت شغلى كاركنان، مىتواند باعث كاهش شكايات و كاهش

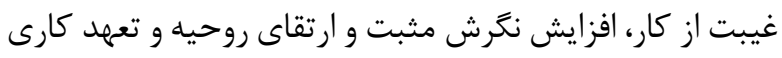

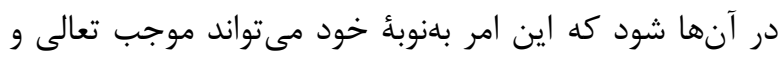

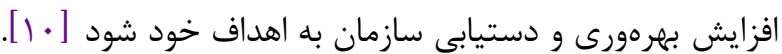
زمانى كه شرايط و ساختار كارى با منابع انسانى در توازن بانئ باشند،

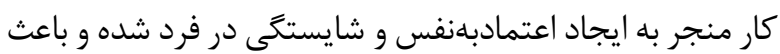

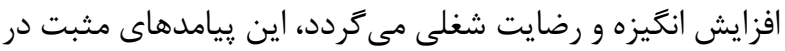
نهايت بهبود سلامتى و عملكرد شغلى مناسب را بهايت كردنبال خواهند داشت [1/].

باتوجه به جميع مطالب مذكور و همجنين توجه به اين نكته

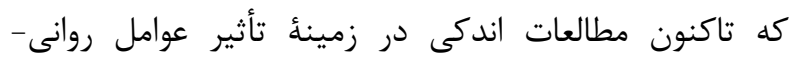

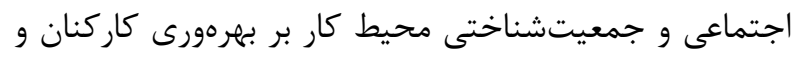
ارتباط آنها با يكديكر انجام شده است؛ لذا اين مطالعه با هدف

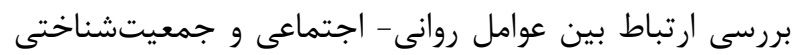

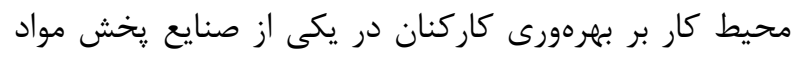

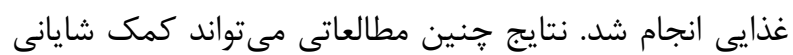
به بهبود عملكرد كارى كاركنان و كنترل وضعيت سلامت جامعه

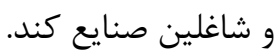

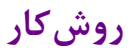

مطالعة مقطعى و توصيفى- تحليلى حاضر در سال 99 11 و

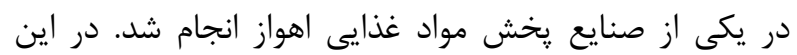

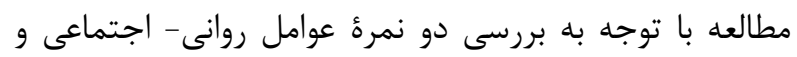

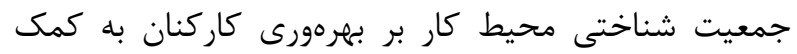

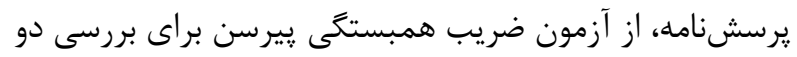

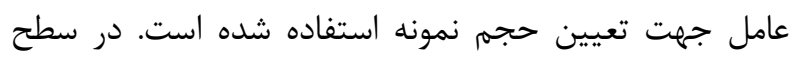

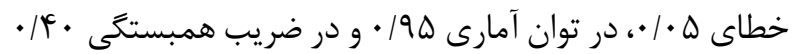

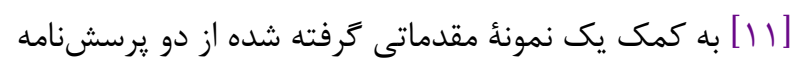

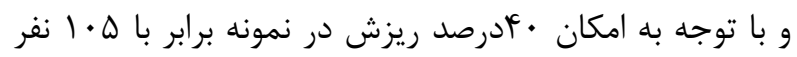

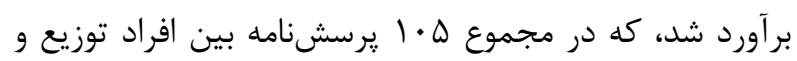
جمع آورى كرديد.

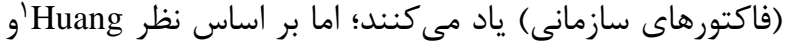

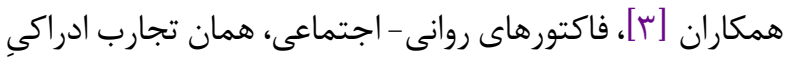

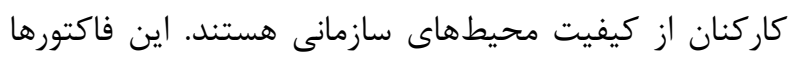

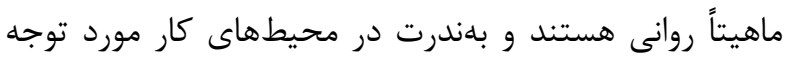

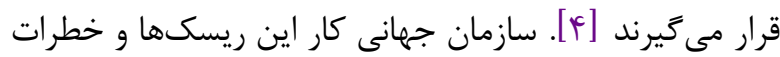
را بدين صورت تعريف مىنمايد: تعاملات بين محيط كار، محتواى شغلى، وضعيتهاى سازمانى و توانايىهاى كاركران،

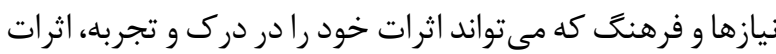

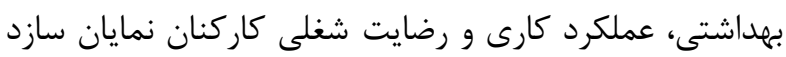

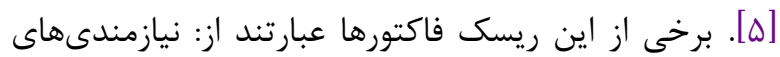

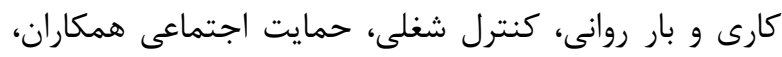
احساس حضور در جامعه، بازخورد مديريتى، كيفيت رهبر رهبرى،

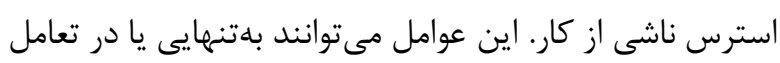

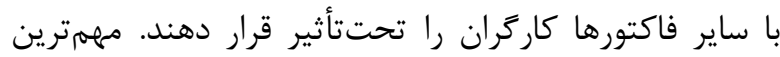

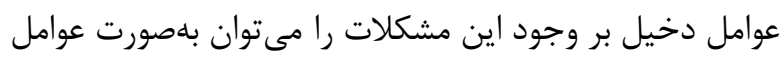

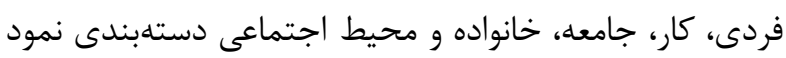

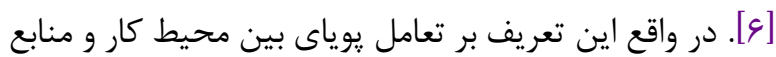

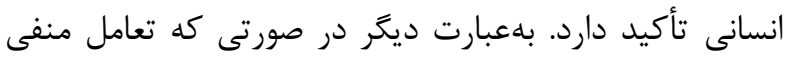

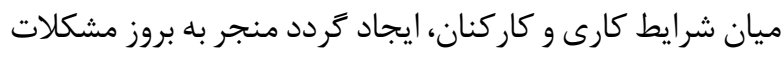

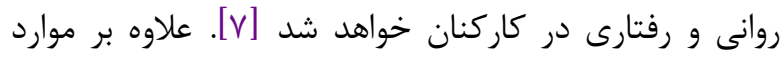
يادشده اين تعامل منفى مىتواند منجر به خستكى، كاهش

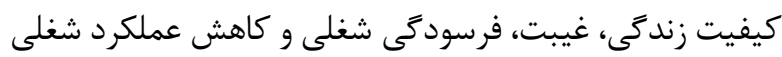

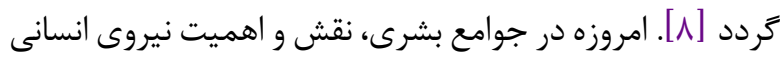

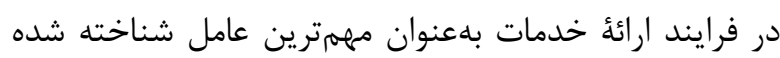

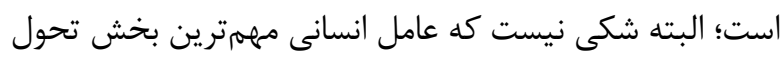

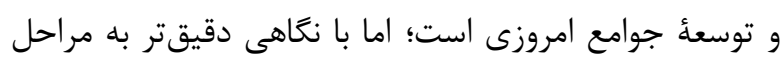

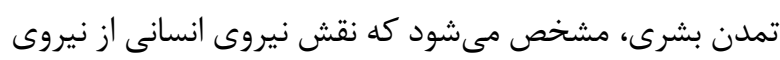
كار ساده (قدرت بازو و كار مكانيكى)، به سرمايئ انسانى (دانش

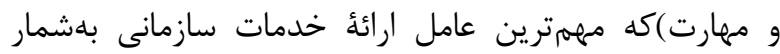

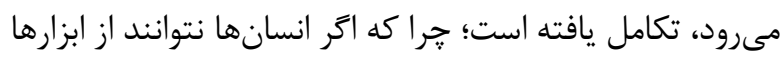
و تجهيزات ييشرفته و تكنولوزى استفاده مطلوب نمايند، عملاً

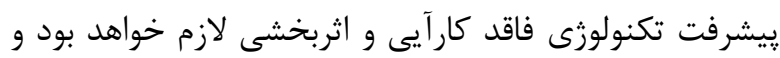

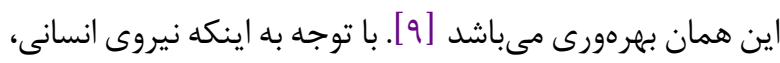

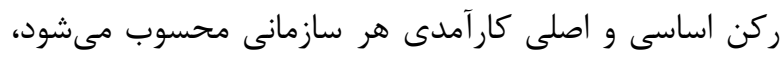

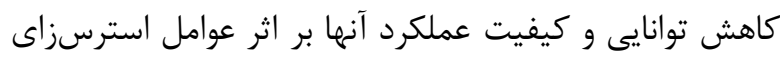

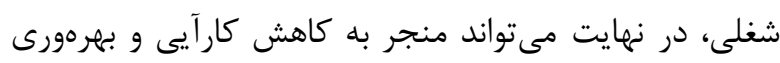




$$
n=\frac{\left(Z_{1-\frac{\alpha}{2}}+Z_{1-\beta}\right)^{2}}{\left(0.5 \ln \left(\frac{1+r}{1-r}\right)\right)^{2}}+3=\frac{(1.96+1.64)^{2}}{\left(0.5 \ln \left(\frac{1+0.4}{1-0.4}\right)\right)^{2}}+3=72+3=75
$$

يرسشنامئ بهرهورى هرسى كلداسميت: براى ارزيابى ميزان

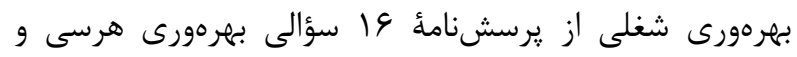

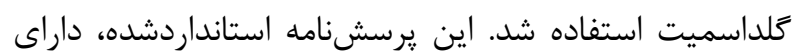

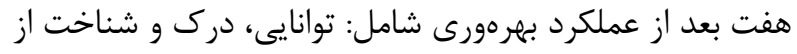

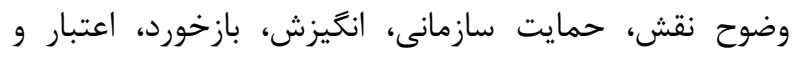

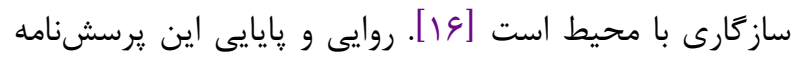
توسط Ardestani و همكاران مورد بررسى قرار كرفت. ميزان

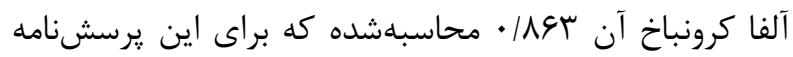

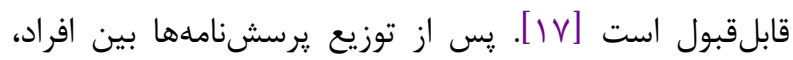

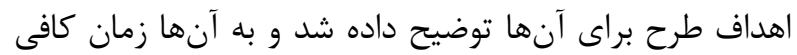

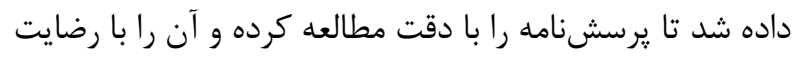

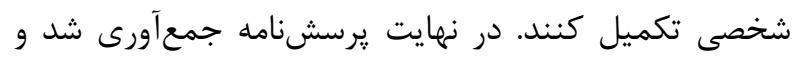

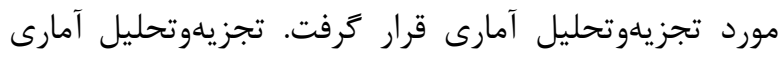

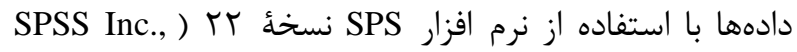
(Chicago, Ill., USA

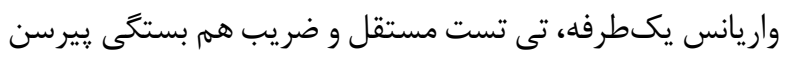

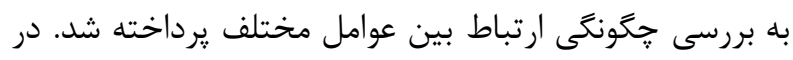
اين مطالعه سطح معنادارى ه درصد در نظر كرفته شد.

\section{يافته ها}

جدول 1 نتايج اطلاعات دموگرافيك افراد شركت كننده در

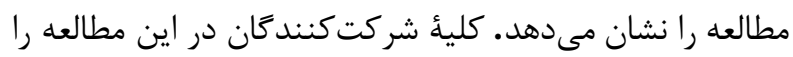

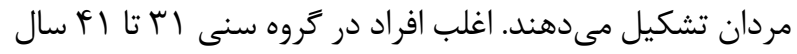

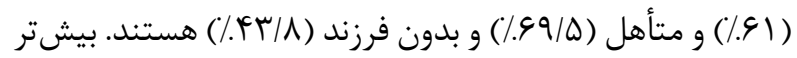

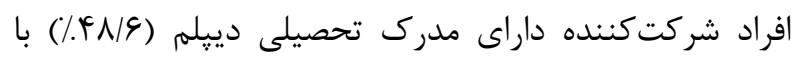

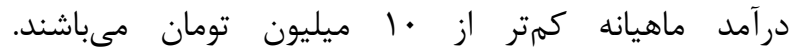

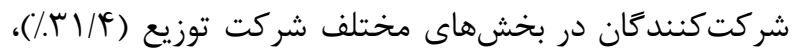

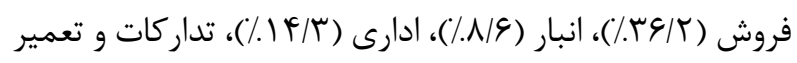

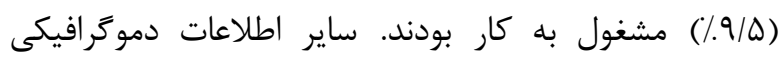
شركت كنندكان در جدول آ آورده شده است.
ابزار جمع آورى دادهها در اين مطالعه شامل: ا-يرسشنامة

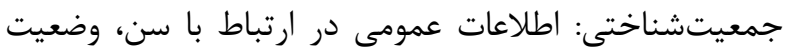

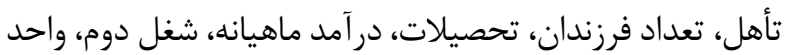

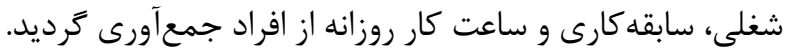

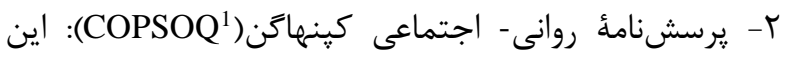

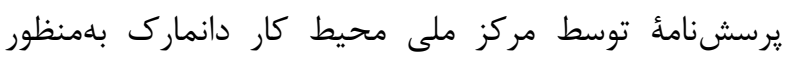

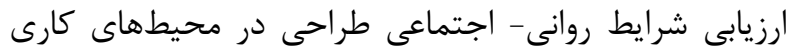

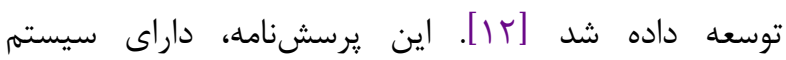
نمرهكذارى خاص خود مى باشد و مى توان ابعاد داراى نقاط ضعنف را در آن مشخص نمود. يرسشنامهٔ روانى- اجتماعى كينهاكن يكى از جامعترين ابزارهاى ارزيابى كننده عوامل استرسزاى نداى

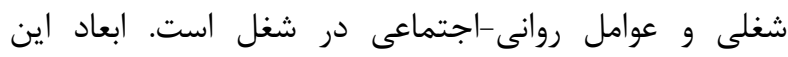

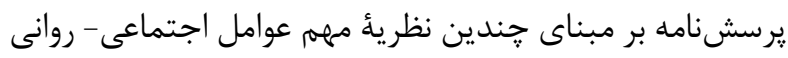
در كار (بدون اتكا به يك نظرئ خاص) طراحى و توسعه داده

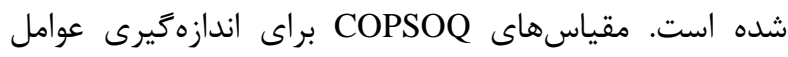

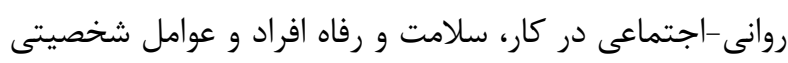
مانند راهبرد (سبك) مقابلهاى2 و احساس انسجام(SOC)

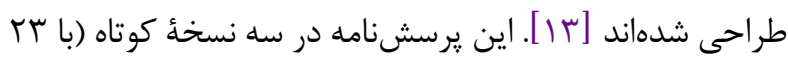

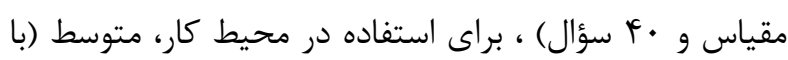

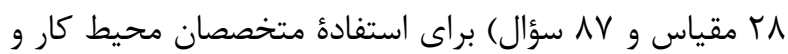

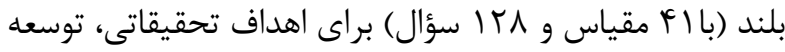

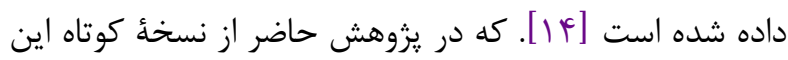

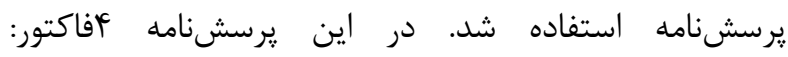
فاكتور ا(كيفيت رهبرى، حمايت اجتماعى از طرف سريرستانيان

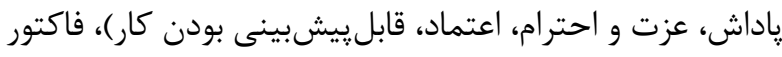

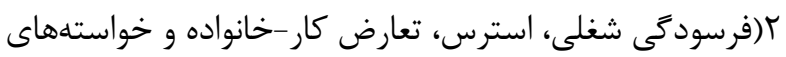

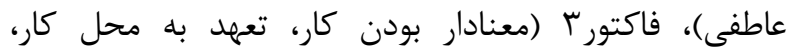

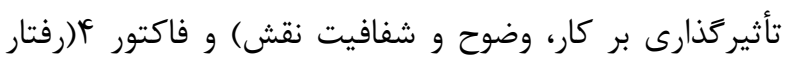

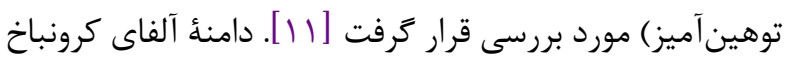

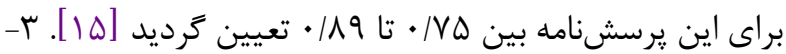


جدول ا. نتايج اطلاعات دموكَرافيك شركت كنندگًان در مطالعه

\begin{tabular}{|c|c|c|c|}
\hline درصد & 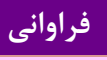 & متغير & \\
\hline$\%$ YY/A & re & كمتر از •r سال & \multirow{3}{*}{ سن } \\
\hline$\% .91$ & $g 4$ & آب الى أF سال & \\
\hline$\%$. & 10 & بيشتر از • f سال & \\
\hline$\% \pi \cdot 10$ & rt & مجرد & وضعيت تاهل \\
\hline$\% .99 / 0$ & Vr & متاهل & \\
\hline$\% F r / \Lambda$ & is & 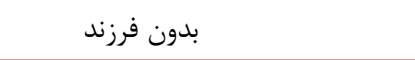 & \multirow{4}{*}{ ت تعداد فرزندان } \\
\hline$\% \pi / \Lambda$ & ra & يك فرزند & \\
\hline$\% \wedge / 1$ & 19 & 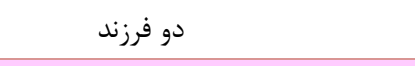 & \\
\hline$\% 14 / \mu$ & 10 & سه فرزند و بيشتر & \\
\hline$\%(4)$ & Fr & زير ديڤلم & \multirow{4}{*}{ تحصيلات } \\
\hline$\% \mathscr{F} / \mathscr{G}$ & DI & دييلمم & \\
\hline$\% 1 \cdot 10$ & 11 & كاردانى / ليسانس & \\
\hline$\%$ & . & كارشناسى ارشد/ دكترى & \\
\hline$\%$ & 91 & كمتر از · ا ميليون تومان & در آمد ماهيانه \\
\hline$\% .9 / \mathrm{V}$ & v & بيش از · إ ميليون تومان & \\
\hline$\% / \Delta / V$ & 4 & 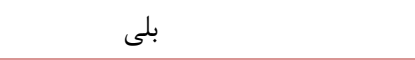 & \multirow{2}{*}{ شغل دوم } \\
\hline$\% 94 / 4$ & 99 & خير & \\
\hline$\%$ & 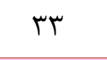 & 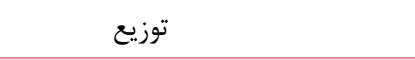 & \multirow{5}{*}{ واحد شغلى } \\
\hline \% & ґ & 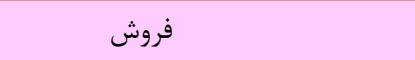 & \\
\hline$\% / .19$ & 9 & 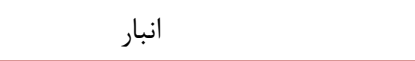 & \\
\hline$\%$ & 10 & ادارى & \\
\hline$\% / 9$ & $1 \cdot$ & تداركات و تعميرات & \\
\hline$\%$ \% & f. & ت ت ا ب سال & \multirow{4}{*}{ سابقه كار } \\
\hline$\% 11 / 4$ & it & بين r تا ه سال & \\
\hline$\%$ & TI & بين ه تا ^ سال & \\
\hline$\%$ & rt & بيشتر از ^ سال & \\
\hline 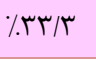 & r山 & 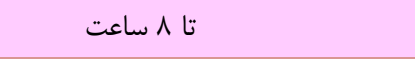 & \multirow{3}{*}{ ساعت كارى } \\
\hline$\% .91$ & sq & بين 1 تا Fا & \\
\hline$\% / \Delta / V$ & 4 & rا ساعت به بالا & \\
\hline
\end{tabular}

يزوهش مىباشد. و ميانگين امتياز بهرهورى جامعهُ مورد بررسى .

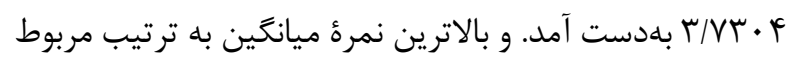

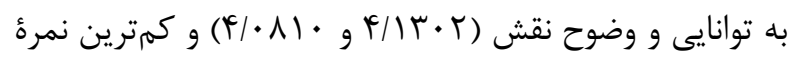

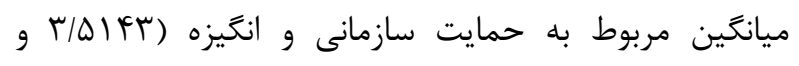

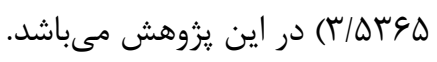

طبق جدول شماره r ميانخين امتياز فاكتورهاى روانى - جانى

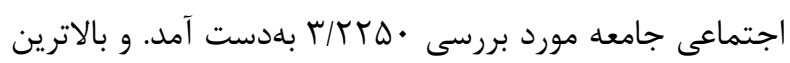

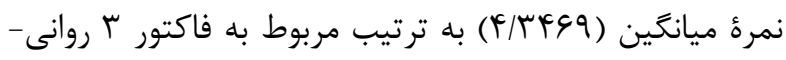
اجتماعى (معنادار بودن كار، تعهد به محل كار، تأثير گذارى بر كار، وضوح و شفافيت نقش) و كمترين نمره ميانگين ( I/VIF) مربوط به فاكتور \& روانى - اجتماعى (رفتار توهين آميز) در اين تهين 


\begin{tabular}{|c|c|c|c|c|c|}
\hline محدوده امتياز & انحراف معيار & ميانكَين & بيشترين & كمترين & شاخص ها \\
\hline $1-0$ & • K499. & r/rTa. & r/qV & T/FF & ميانغين امتياز فاكتورهاى روانى - اجتماعى \\
\hline $1-\Delta$ & - |A|FVA & $r / \Delta$ & $\Delta$ & $1 / T \Delta$ & فاكتور 1 \\
\hline $1-\Delta$ & - IVTFFY & T/VDAr & $f / Q$ & $1 / 0$ & فاكتور r \\
\hline $1-\Delta$ & $\cdot 190 \cdot r \cdot$ & $F / T<\notin q$ & $\Delta$ & $t / 4$ & فاكتور r \\
\hline $1-\Delta$ & $\cdot \mid V r \cdot 91$ & $1 / V+1$ & $r / \Lambda$ & $\cdot / 1$ & فاكتور F F \\
\hline $1-\Delta$ & - $/ D \Delta \cdot r r$ & $r / V r \cdot r$ & $\Delta$ & $r / 19$ & ميانگين امتياز بهره ورى \\
\hline $1-\Delta$ & $\cdot / 2 \cdot 1 V 9$ & $k / l r \cdot r$ & $\Delta$ & T/T & 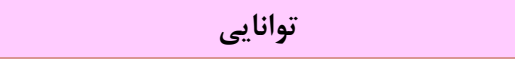 \\
\hline $1-\Delta$ & - IEATEY & $\varphi / \wedge 1$ & $\Delta$ & r & وضوح نقش \\
\hline $1-\Delta$ & $\cdot / 9 r 4 \cdot t$ & r/DIFT & $\Delta$ & 1 & حمايت سازمانى \\
\hline $1-\Delta$ & - /VATI9 & $r / \Delta r \xi \Delta$ & $\Delta$ & $1 / 9 V$ & انغَيزه \\
\hline $1-\Delta$ & $\cdot \mid A F \cdot G T$ & r/GVGT & $\Delta$ & $1 / 0$ & بازخورد \\
\hline $1-\Delta$ & $\cdot|1| 901$ & r/GFTq & $\Delta$ & 1 & 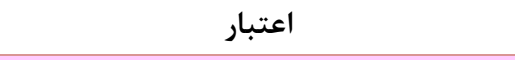 \\
\hline $1-\Delta$ & - /9rAVA & T/FTAS & $\Delta$ & 1 & سازگارى با محيط \\
\hline
\end{tabular}

در جدول r ر رابطئ بين مشخصات دموكرافيك با امتياز بين هيج يك از متغيرهاى جمعيتشناختى با امتياز فاكتورهاى

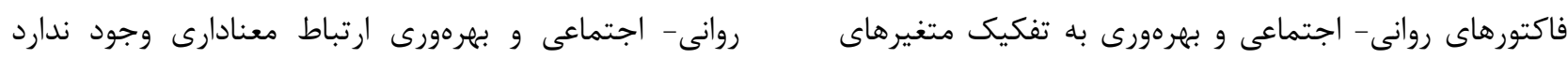

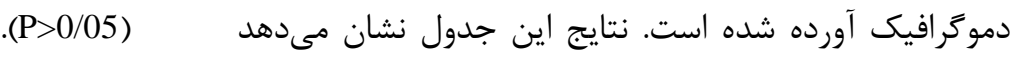

جدول r. رابطُ بين مشخصات دموتر افيك با امتياز فاكتور هاى روانى - اجتماعى و بهرهورى

\begin{tabular}{|c|c|c|c|}
\hline سطح معنى دارى با بهره ورى & سطح معنى دارى با فاكتور هاى روانى - اجتماعى & 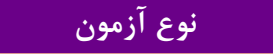 & 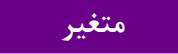 \\
\hline 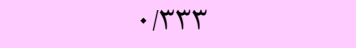 & $\cdot|r F|$ & آناليز واريانس يك طرفه & 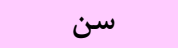 \\
\hline$.|| \Delta \mid$ & - /TAT & آناليز واريانس يك طرفه & تعداد فرزندان \\
\hline .1190 & $\cdot / l \Delta T$ & آزمون تى مستقل & 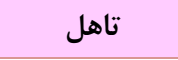 \\
\hline . I995 &.$/ 1 F \Delta$ & آناليز واريانس يك طرفه & ت تحصيلات \\
\hline$\cdot / 9 \Delta \wedge$ & •/ १९६ & آزمون تى مستقل & در آمد ماهيانه \\
\hline 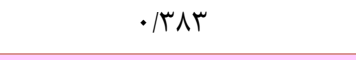 & $\cdot / V F$ & آزمون تى مستقل & 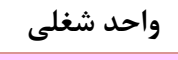 \\
\hline $.19 \Delta \Lambda$ & $\cdot \operatorname{lq94}$ & آزمون تى مستقل & شغل دوم \\
\hline 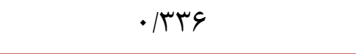 & $\cdot 1 \wedge 9$ & آناليز واريانس يك طرفه & سابقه كار \\
\hline .1994 & $\cdot|49|$ & آناليز واريانس يك طرفه & 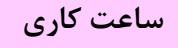 \\
\hline
\end{tabular}

ارتباط منفى و معنادارى دارد. مطابق جدول fأ، ميانگين امتياز

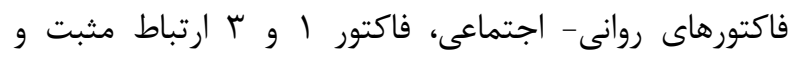

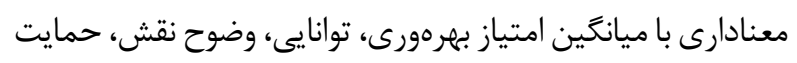

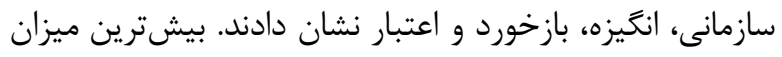

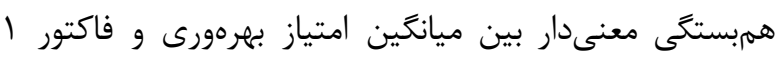

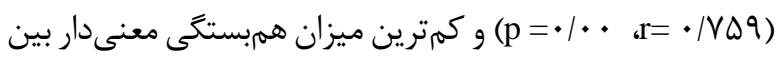

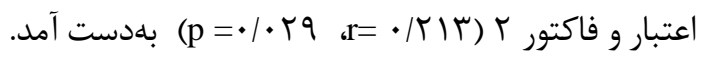

جهت بررسى ارتباط بين مقادير ابعاد عوامل روانى- اجتماعى

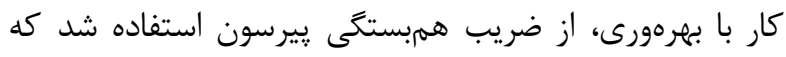

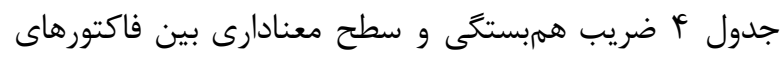

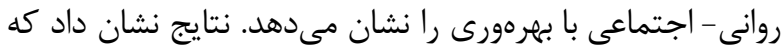

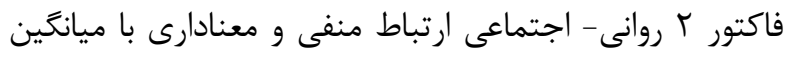

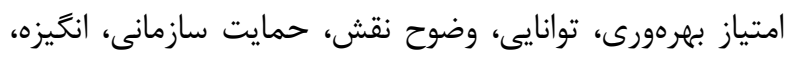

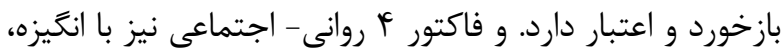


جدول f. ضريب همبستكى و سطح معنادارى بين فاكتورهاى روانى - اجتماعى با بهرهورى

\begin{tabular}{|c|c|c|c|c|c|c|}
\hline فاكتور F & فاكتور r & فاكتور r & فاكتور & ميانَين امتياز فاكتور هاى روانى - اجتماعى & & \\
\hline$-\cdot / 1 r a$ & $\cdot 1 \Delta 99$ & $-\cdot$ - Kat & $\cdot / V \Delta q$ & $\cdot \mid 91$ & ضريب همبستخى & ميانگين امتياز بهره \\
\hline$\cdot / 1 \mathrm{~V}$ & $\cdot 1 \cdot \cdots *$ & $\cdot / \cdot V^{*}$ & $\cdot 1 \cdot \ldots *$ & $\cdot 1 \cdot{ }^{*}$ & سطح معنادارى & \\
\hline$-\cdot 1.9 T$ & ./4qT & $-\cdot / T F \Delta$ & - $/ \Delta F q$ & $\cdot 10 \cdot 9$ & ضريب همبستكى & 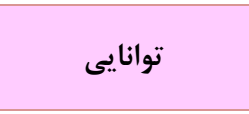 \\
\hline - IDTV & $\cdot 1 \cdots *$ & $\cdot / \cdot 1 r^{*}$ & $\cdot 1 \cdots *$ & $\cdot 1 \cdots *$ & سطح معنادارى & \\
\hline$-\cdot / T V$ & $\cdot 1019$ & r & . & . IDTV & ضريب همبستگى & وضوح نقش \\
\hline$\cdot 1191$ & $\cdot 1 \cdots *$ & $\cdot \cdot \cdot r^{*}$ & $\cdot 1 \ldots *$ & $\cdot 1 \ldots *$ & سطح معنادارى & \\
\hline$-\cdot / l \Delta V$ & $\cdot / 4 \cdot r$ & -• & $\cdot 19 \cdot 9$ & - IFFs & ضريب همبستخى & حمايت سازمانى \\
\hline .1111 & $\cdot 1 \cdots *$ & $\cdot 1 \cdots *$ & $\cdot 1 \cdot \cdots *$ & $\cdot 1 \cdots *$ & سطح معنادارى & \\
\hline$-\cdot / r a r$ & $\cdot|F Y|$ & $-\cdot / \pi \cdot 9$ & .1999 & $\cdot|\Delta| \cdot$ & ضريب همبستخى & انغيزه \\
\hline$\cdot 1 \cdot \cdot 9 *$ & $\cdot 1 \cdot \cdots *$ & $\cdot 1 \cdot \cdot 1^{*}$ & $\cdot 1 \ldots *$ & $\cdot 1 \cdots *$ & سطح معنادارى & \\
\hline$-\cdot / \cdot F V$ & - IDTF & $-\cdot /$ TFF & - /VYq & - IqVD & ضريب همبستكى & بازخورد \\
\hline ת r & $\cdot 1 \cdot \ldots *$ & $\cdot 1 \cdot 1 r^{*}$ & $\cdot / \ldots *$ & $\cdot 1 \ldots *$ & سطح معنادارى & \\
\hline$-\cdot / 1 \Lambda$ &.$/ 489$ & $-\cdot / r \mid r$ & - IDTK & . /4\& & ضريب همبستخى & اعتبار \\
\hline .1 .94 & $\cdot 1 \ldots *$ & $\cdot / \cdot r q^{*}$ & $\cdot 1 \cdots *$ & $\cdot 1 \ldots *$ & سطح معنادارى & \\
\hline$\cdot / 1 \wedge 9$ & $-\cdot / \cdot v \varepsilon$ & - MGT & $-\cdot 1 \cdot r q$ & $\cdot / 1 \wedge \wedge$ & ضريب همبستكى & سازَارى با محيط \\
\hline$\cdot 1 \cdot \Delta V$ & . MFt & $\cdot 1 \cdots *$ & •/Vqr & $\cdot 1 \cdot \Delta F$ & سطح معنادارى & \\
\hline
\end{tabular}

شغلى، استرس، تعارض كار خانواده و خواستههاى عاطفى، بهرهورى، توانايى، وضوح نقش، حمايت سازمانى، انخيزه، بازخورد و اعتبار افراد

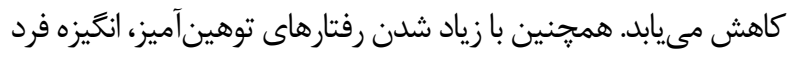
كاهش جشمَيرى بيدا خواهد كرد.

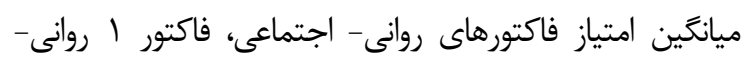

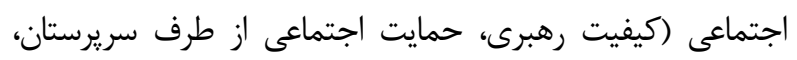

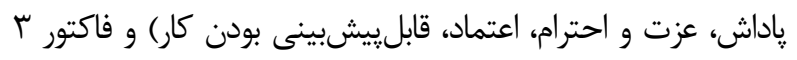

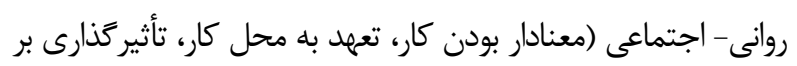
كار، وضوح و شفافيت نقش) ارتباط مثبت و معنادارى با ميانخين امتياز

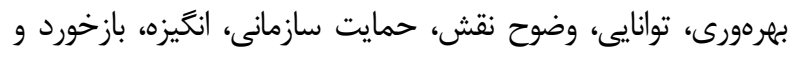

مطالعه حاضر اولين مطالعهاى بود كه با هدف بررسى ارتباط بين

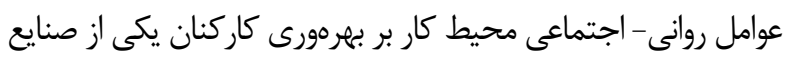

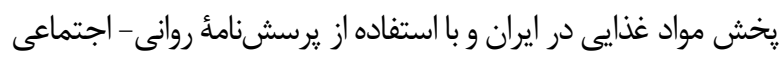

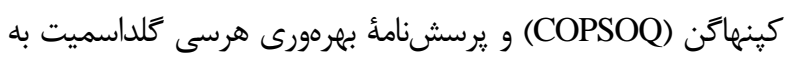

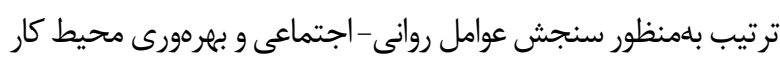
انجام كرفت.

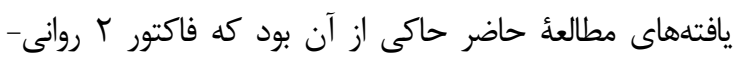

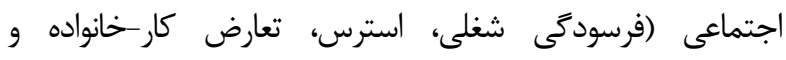

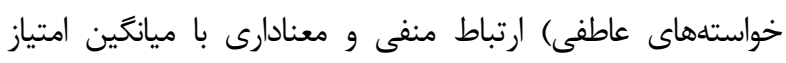

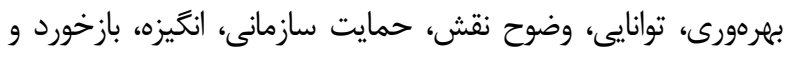

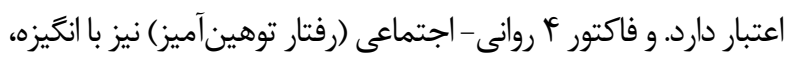

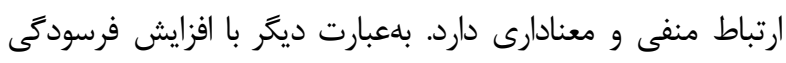


فاكتورهاى روانى - اجتماعى محيط كار مىتواند بر بهرهورى و سلامت

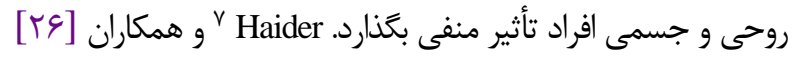

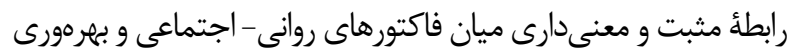

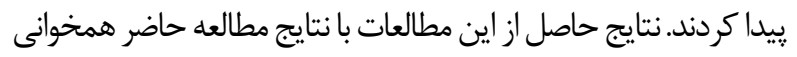

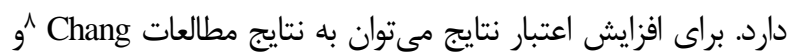

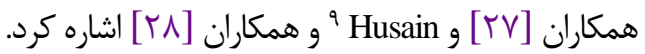

\section{نتيجه}

همانكونه كه مشاهده كرديد، برخى از ابعاد روانى-اجتماعى داراى ارتباط معنى دارى با بهرهورى بودند. اين فاكتورها حاكى از از وجود برخى مشكلات در محيط كار است كه مى بواند به عنوان كزينههاى اصلاحى جهت ارتقاء شرايط محيط كار مدنظر قرار داده

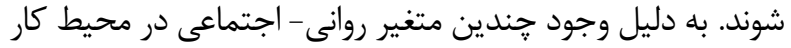

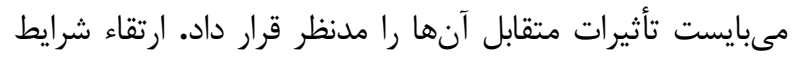

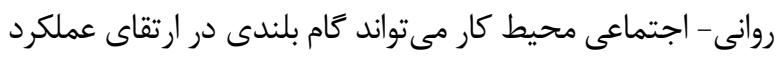

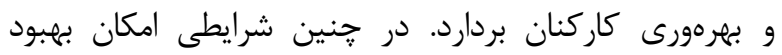

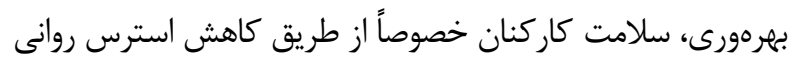

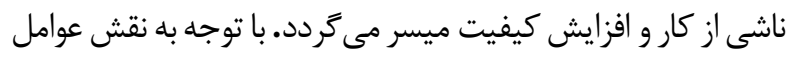
روانى- اجتماعى محيط كار بر بهرهورى كاركنان، لازم است مداخلات سازمانى بدمنظور كنترل عوامل روانى - اجتماعى مؤثر،

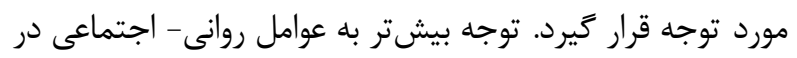

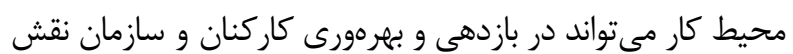
مؤثرى ايفانمايد.

همجنين نشان داده شد كه بين متغيرهاى جمعيت شناختى

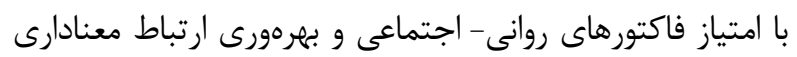
وجود ندارد. على رغم وجود اين احتمال كه انتظار مىرفت ميان مشخصات دموكرافيك در ارتباط با سن، وضعيت تأهل، تعدئ تعداد

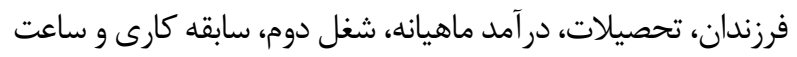
كار روزانه با فاكتورهاى روانى- اجتماعى و بهرهورى ارتباط

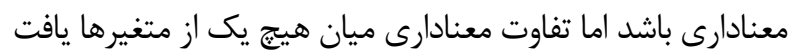

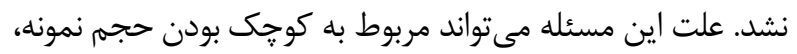
تكميل يرسشنامهها در محل كار و يا وجود مشغله كارى شركت كنندكان باشد و امكان دارد افراد با خستكى و عدم تمد تمركز

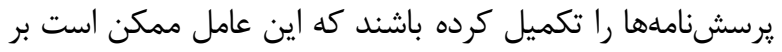

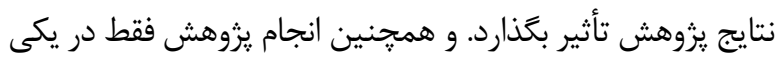

${ }^{6}$ Cho

${ }^{7}$ Haider

8 Chang

${ }^{9}$ Husain
اعتبار نشان دادند. يافتههاى يزوهش حاضر با نتايج يزوهش 'Hinojosa-Alcalde و وممكاران [1/] همسو بوده است.

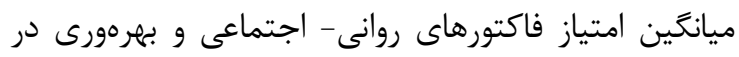

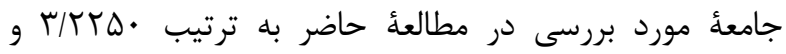
Khanehshenas و و همكاران [19] كه به بررسى ارتباط عوامل استرسزاى روانى- اجتماعى كار با عملكرد شغلى در بين كاركنان بانك يرداخته بود، ميانكين

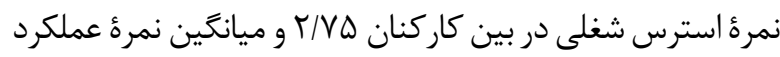

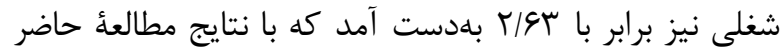
مطابقت ندارد كه اين امر مىتواند ناشى از متفاوت بودن جامعائ

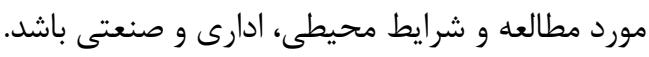

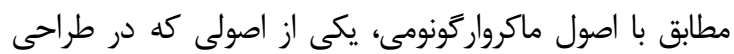
مشاغل بايد مدنظر قرار گيرد، رعايت اصل برآررده كردن نيازهاى

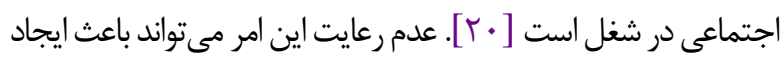
استرس شغلى و بروز مشكلات سلامتى براى كاركنان شود كه در

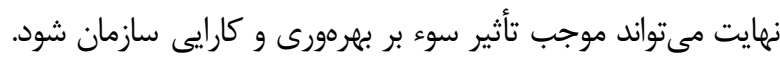

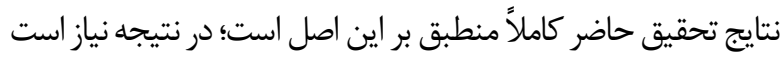

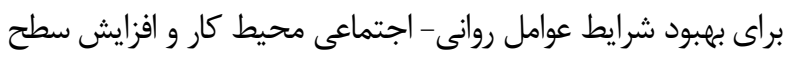
بهرهورى كاركنان، توجه بيشترى به اين اصل شود. همانطور كه نتايج

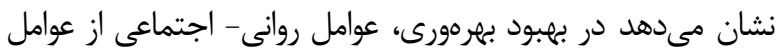

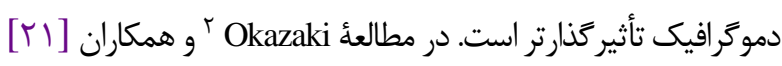

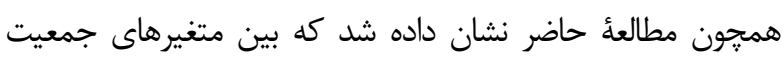

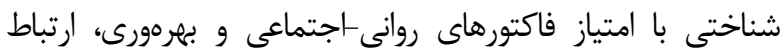

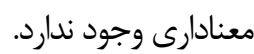
همانطور كه بيان شد عوامل روانى- اجتماعى محيط كار از مهمترين عوامل مؤثر بر بجرهورى كاركنان محسوب مي تشود كهد ارتباط

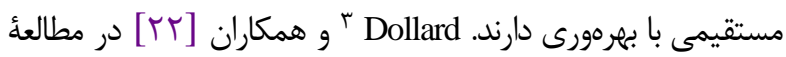
خود نشان دادند كه عوامل روانى- اجتماعى در بهيبود بجرهورى و

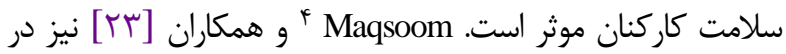

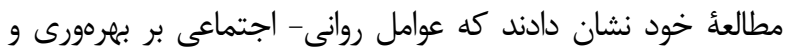

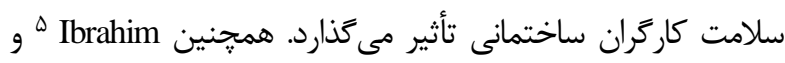

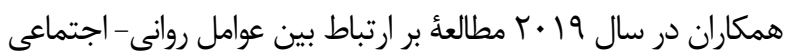
و بهرهورى مراقبتهاى بهداشتى انجام دادند كه نشان داد عوامل

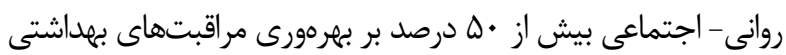

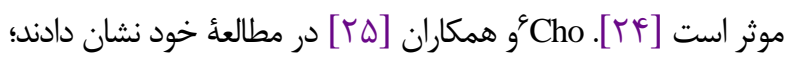

\footnotetext{
${ }^{1}$ Hinojosa-Alcalde

${ }^{2}$ Okazaki

${ }^{3}$ Dollard

${ }^{4}$ Maqsoom

${ }^{5}$ Ibrahim
} 


$$
\begin{aligned}
& \text { مورد مطالعه، كه در انجام اين :يزوهش، صميمانه ما را يارى } \\
& \text { نمودند، تشكر و قدردانى مى گردد. } \\
& \text { تعارض منافع } \\
& \text { بين نويسند گان هيج گَونه تعارضى در منافع وجود ندارد. } \\
& \text { منابع مالى }
\end{aligned}
$$

\section{References}

1. Kristensen TS, Hannerz H, Høgh A, Borg V. The Copenhagen Psychosocial Questionnaire-a tool for the assessment and improvement of the psychosocial work environment. Scand J Work, Environ Health. 2005; 1:438-49. [DOI:10.5271/sjweh.948] [PMID]

2. Gerber M, Pühse U. "Don't crack under pressure!"-Do leisure time physical activity and self-esteem moderate the relationship between school-based stress and psychosomatic complaints?. J Psychosom Res. 2008; 65(4):363-9. [DOI:10.1016/j.jpsychores.2008.06.012] [PMID]

3. Houtman IL, Bongers PM, Smulders PG, Kompier MA. Psychosocial stress'sors at work and musculoskeletal problems. Scand J Work, Environ Health. 1994; 1:13945. [DOI: 10.5271/sjweh.1419] [PMID]

4. Osborn RL, Demoncada AC, Feuerstein M. Psychosocial interventions for depression, anxiety, and quality of life in cancer survivors: meta-analyses. Int J Psychiat Med. 2006; 36(1):13-34. [DOI:10.2190/EUFN-RV1K-Y3TR-FK0L] [PMID]

5. Pillinger J. Psychosocial risks and violence in the world of work: A trade :union: perspective. Int J Labour Res. 2016; $8(1 / 2): 35$.

6. Gold D, Caborn J. Addressing psychosocial problems at work. Dr. Helsinki Work. Work. Health Promot. 2006.

7. Leka S, Griffiths A, Cox T, World Health Organization. Work organisation and stress: systematic problem approaches for employers, managers and trade :union: representatives. World Health Organ 2003.

8. Milczarek M, Brun E, Houtman I, Goudswaard A, Evers M, Bovenkamp M, Roskams N, Op de Beeck R, Pahkin K, Berthet M, Morvan E. Expert forecast on emerging psychosocial risks related to occupational safety and health;2007.

9. Paydarfard, D, Abbaszadeh, Y, Fanni, M, Hamdi, K. Relationship between Employees' Work-life Quality and Human Power Productivity in Islamic Azad University Branches of Salmas, Khoy, and Urumia. The J Product Manag. 2015; 9(1(32)): 89-108.

10. Mokarami H, Stallones L, Nazifi M, Taghavi SM. The role of psychosocial and physical work-related factors on the health-related quality of life of Iranian industrial

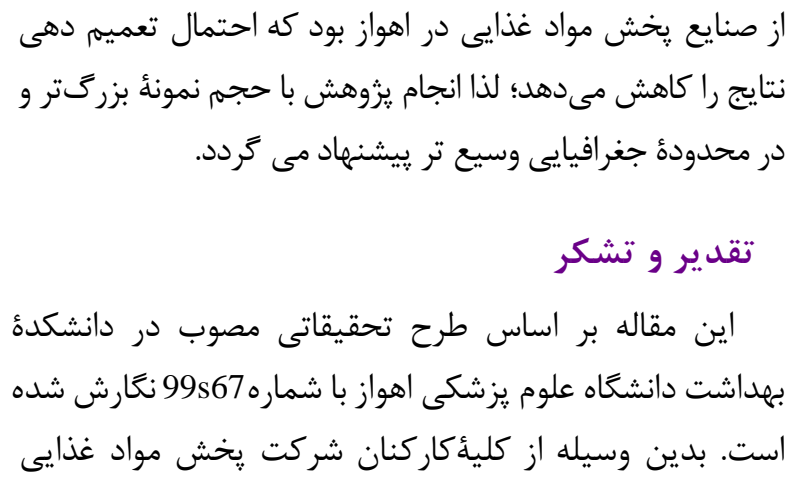

workers. Work. 2016; 55(2):441-52.

[DOI:10.3233/WOR-162405] [PMID]

11. Baleshzar A, Tabodi M, Rojhani Shirazi Z. The Relationship Between Environmental and Demographic Factors with Productivity of Islamic Azad University of Shiraz Employees. Iran J Ergon. 2019; 7(2):39-44.

12. Kristensen TS. A new tool for assessing psychosocial factors at work: The Copenhagen Psychosocial Questionnaire. TUTB Newsl. 2002; 19(20):45-7.

13. Kristensen TS, Hannerz H, Høgh A, Borg V. The Copenhagen Psychosocial Questionnaire-a tool for the assessment and improvement of the psychosocial work environment. Scand J work Environ Health. 2005; 1:438-49. [DOI: 10.5271/sjweh.948] [PMID]

14. Pejtersen JH, Kristensen TS, Borg V, Bjorner JB. The second version of the Copenhagen Psychosocial Questionnaire. Scand J Public Health. 2010; 38(3_suppl):8-24. [DOI:10.1177/1403494809349858] [PMID]

15. Aminian M, Dianat I, Miri A, Asghari-Jafarabadi M. The Iranian version of the Copenhagen Psychosocial Questionnaire (COPSOQ) for assessment of psychological risk factors at work. Health Promot Perspect. 2017; 7(1):7. [DOI:10.15171/hpp.2017.03] [PMID] [PMCID]

16. Hersey P, Goldsmith M. A situational approach to performance planning. J Train Dev. 1980; 34(11):38-+.

17. Ardestani S, Momeni M, Marjani A. Study of Factors Affecting Employee Performance (Case Study: Bank Melli West Tehran Branches), International Conference on Management, Challenges and Solutions; 2013; Shiraz, Iran.

18. Hinojosa-Alcalde I, Andrés A, Didymus FF, Norman L, Soler S. Assessing Psychosocial Work Environments of Coaches in Spain and Their Relationships With Mental Health, Behavioral-Stress Symptoms, and Burnout. Sport Psychol. 2020; 1(aop):1-0.

19. Khanehshenas F, Allahyari T. Investigation of the relationship between psychosocial stressors and job performance among bank employees. Iran J Ergon. 2014; 1(3):1-0. 
20. Hendrick HW, Kleiner BM. Macroergonomics: Macroergonomics: Theory, Methods, and Applications (1st ed.). CRC Press.; 2002. [DOI:10.1201/b12477]

21. Okazaki E, Nishi D, Susukida R, Inoue A, Shimazu A, Tsutsumi A. Association between working hours, work engagement, and work productivity in employees: A cross-sectional study of the Japanese Study of Health, Occupation, and Psychosocial Factors Relates Equity. J Occup Health. 2019; 61(2):182-8. [DOI:10.1002/13489585.12023] [PMID] [PMCID]

22. Dollard MF, Neser DY. Worker health is good for the economy: :union: density and psychosocial safety climate as determinants of country differences in worker health and productivity in 31 European countries. Soc Sci Med. 2013; 92:114-23. [DOI:10.1016/j.socscimed.2013.04.028] [PMID]

23. Maqsoom A, Mughees A, Khan AK, Arif MI. Investigating the Influence of Internal Psychosocial Stressors. Am Soc Civil Eng. 2018; 3:10-17.

24. Ibrahim MA, Aziz AA, Suhaili NA, Daud AZ, Naing L, Rahman HA. A Study into Psychosocial Work Stressors and Health Care Productivity. Int J Occup Environ Med. 2019; 10(4):185. [DOI:10.15171/ijoem.2019.1610] [PMID] [PMCID]
25. Cho YS, Park JB, Lee KJ, Min KB, Baek CI. The association between Korean workers' presenteeism and psychosocial factors within workplaces. Ann Occup Environ Med. 2016; 28(1):41. [DOI:10.1186/s40557016-0124-1] [PMID] [PMCID]

26. Haider S, Jabeen S, Ahmad J. Moderated mediation between work life balance and employee job performance: The role of psychological wellbeing and satisfaction with coworkers. J Work Organ Psychol. 2018; 34(1):29-37. [DOI:10.5093/jwop2018a4]

27. Chang C, Putukian M, Aerni G, Diamond A, Hong G, Ingram Y, Reardon CL, Wolanin A. Mental health issues and psychological factors in athletes: detection, management, effect on performance and prevention: American Medical Society for Sports Medicine Position Statement-Executive Summary. Br J sports Med. 2020; 54(4):216-20. [DOI:10.1136/bjsports2019-101583] [PMID]

28. Husain NA, Mohamad J. Validation of The COPSOQ and BDJD-24 as a Job Demand Scale For Assing Taxi Driver'safety Performance: Spcific Vs. General Job Demands. J Health and Transl Med. 2020; 23:41-51 